\title{
Prevention through Learning: working together to drive high-quality care
}

D Bell ${ }^{1}$, A Paterson $^{2}$, G McAlister ${ }^{3}$

Declaration of interests: No conflict of interests declared

\author{
Correspondence to: \\ G McAlister \\ Royal College of Physicians \\ of Edinburgh \\ 9 Queen Street \\ Edinburgh EH2 1JQ \\ Email: \\ g.mcalister@rcpe.ac.uk
}

\section{Context}

In May 2015 the Academy of Medical Royal Colleges and Faculties in Scotland published a report on Learning from Serious Failings in Care. ${ }^{1}$ This reviewed the reports on failings experienced in Mid Staffordshire, Lanarkshire, Vale of Leven and Aberdeen and made a series of recommendations regarding how the NHS in Scotland could learn from these failings and prevent recurrence. It became clear that poor team working and engagement between managers and clinicians had been recurring factors and contributed to these failings. Recognising the need to consider how we could best collectively address these deficiencies, the Scottish Academy convened a meeting in October 2015. Invited stakeholders included NHS Board Chairs, Chief Executives, Medical Directors, representatives of the Royal Colleges and other related medical and nursing organisations including NHS Healthcare Improvement Scotland and RCN Scotland. The report and evening meeting provided a catalyst for change and for progressing our aim of delivering the highest possible quality of care. Reflecting the need for managers and clinicians to work more effectively together, and our desire to lead by example, the Scottish Academy partnered with the Scottish Institute of Health Management and agreed to convene two events with the support of the Good Governance Institute - the first in a series of workshops for NHS Board Non-Executive Directors (31 October 2016) and a related national stakeholder meeting (11 November 2016). This paper summarises the national stakeholder meeting.

\section{The national stakeholder meeting}

The meeting took the form of an opening/keynote address followed by a series of presentations from invited speakers (with Q\&A sessions), a panel discussion and summing up. Discussions also took place in the context of related national polices and strategies including the Scottish Government's
Quality Strategy, 2020 Workforce Vision and Realistic Medicine. ${ }^{2-4}$

The event was opened by James Titcombe, whose campaigning led to the Morecambe Bay Inquiry following the death of his baby son nine days after his birth in October 2008 , as a consequence of untreated infection, and author of Joshua's Story. ${ }^{5}$ Delegates heard of Mr Titcombe's repeated attempts to have his concerns investigated properly over a 7-year period including an initial response from the hospital that observation records had been 'lost', two flawed local investigations, an unsuccessful complaint to the Parliamentary and Health Service Ombudsman, a coroner's inquest, a Care Quality Commission inspection report and culminating in a Government commitment in 2013 to hold an independent inquiry, the report of which was published in 2015. The Inquiry report found that there had been a 'lethal mix' of failures which had 'led to the unnecessary deaths of mothers and babies' and that that these failings had occurred 'at almost every level - from the maternity unit to those responsible for regulating and monitoring the Trust'; between 2004 and 2013 at Furness General Hospital there had been 20 instances of significant or major failures of care relating to three maternal deaths and 16 babies' deaths; 11 babies and one mother would have survived with different care. ${ }^{6} \mathrm{Mr}$ Titcombe went on to present evidence which showed that while this had initially been presented as an isolated local failure at 'one small maternity unit', failings of this nature were widespread throughout the NHS. ${ }^{7,8} \mathrm{He}$ focused on recommendations from the report regarding the need for clear standards for incident reporting and investigation, to reinforce the duty of professional staff to report concerns about clinical services, and for a fundamental review of the NHS complaints system. He spoke about the opinion of Don Berwick, one of the leading international quality improvement advocates, that 'healthcare has to choose between safety and fear' and 
highlighted other Inquiries including the Kennedy Report on children's heart surgery at Bristol which recommended that 'learning from error, rather than seeking blame, must be the priority in order to improve safety and quality' and the Francis Report on Mid Staffordshire which noted that 'the NHS has developed a widespread culture more of fear and compliance, than of learning, innovation and enthusiastic participation in improvement'. ${ }^{9,10}$ In closing, he spoke of the need and opportunity to learn lessons from other sectors about how to investigate failings and reduce errors.

Professor Alan Paterson followed with an overview of related work undertaken by the Academy of Medical Royal Colleges and Faculties in Scotland. This had involved reviewing the published reports on failings in care in Mid Staffordshire, Lanarkshire, Vale of Leven and Aberdeen to identify lessons which the NHS in Scotland could learn to prevent recurrence. These findings were published in the Learning from Serious Failings in Care report. Key issues identified included poor leadership from senior medical staff and Board management resulting in a defective culture, inappropriate skills mix, poor staff morale and motivation, poor patient care and communication with patients, inadequate complaints handling, and limitations in external assessment. Professor Paterson highlighted that particularly prominent recurring factors in these reports had been the existence of silo thinking, poor engagement between managers and clinicians and a lack of team working. He then provided an overview of the report's main recommendations covering five domains - Leadership, Culture \& Professional Engagement, Inadequate Staffing, Quality of Care \& Patient Experience and External Review.

Continuing the theme of managerial and medical engagement, Professor Graeme Martin provided an overview of the published literature on this area. He started by looking at the theory regarding what underpins and influences effective leader-follower relations in medicine and healthcare before moving on to focus on what the evidence says regarding manager-doctor relations, including recent research which his team had been commissioned to undertake regarding this in the NHS in Scotland. ${ }^{11}$ This had found a negative spiral in manager-doctor relations with an overall lack of reciprocity in granting of leadership identities, a divergence of views on appropriate leadership structures, a lack of clarity, visibility and credibility of claims to leadership and a low-trust dynamic between managers and doctors. The largest, and most dominant, voice were later career consultants without medical management experience who experienced a range of identity threats including high professional values conflict, high status loss/de-professionalisation, an ambivalence to medical managers and distrust of those who had 'crossed the line'. He then considered the implications of these findings for distributing a range of models of leadership and medical engagement.

Professor June Andrews opened the second morning session with an overview of 'Trusted to Care'. ${ }^{12}$ A relative's concern over poor care for his mother, and subsequent poor complaint handling, in a hospital in Wales had attracted media and political attention which led to the Health Minister calling Professor Andrews in as an independent expert to investigate. Independent scrutiny and investigation of care of older people in the Prince of Wales Hospital, Bridgend, and Neath Port Talbot Hospital highlighted other bad practice which shocked staff and adversely affected staff morale and recruitment. One year on, follow-up noted some improvement in levels of care. Staff were not confident about caring for confused patients and there was little interaction between junior doctors and nurses. Professor Andrews moved on to the area of complaints handling and advised that it is fatal to be slow, to be defensive or to try to mislead, and highlighted the need to recognise swiftly when there is a crisis of confidence in service provision. In closing, she focused on the need to educate and support staff in the areas of law and ethics, self-awareness, basic care skills and confidence in communication.

Mr David Galloway presented an overview of the surgical experience of reducing errors by presenting a series of media articles from 2002-2016 which showed that basic errors such as removing the wrong kidney are still occurring. He then focused on the areas of prevalence, nature and future strategy. On prevalence, a range of data from international literature published since 2000 was presented. Particular attention was given to US data (which it is thought is consistent internationally and in the UK) highlighting that medical error is the 4th leading cause of death, and to a review which found that if surgical mortality could be reduced from 1.5-0.8\%, $1,640,000$ lives could be saved worldwide. ${ }^{13,14}$ After providing an overview of the nature of surgical errors, and the impact of the WHO Surgical Safety Checklist, Mr Galloway moved on to the subject of auditing surgical mortality. He noted that while Scotland had previously led the way through the Scottish Audit of Surgical Mortality, which has now been replicated in many areas internationally, this had unfortunately been discontinued in Scotland. In closing, he highlighted the need to learn from errors and reported on ongoing activity being undertaken by managed clinical networks in Scotland.

Mr Neil Findlay provided an overview of the work of the Scottish Parliament's Heath \& Sport Committee and related Committees with particular emphasis on scrutinising the NHS in Scotland and contributing to quality improvement. He articulated the Health \& Sport Committee's Strategic Plan and Vision for 2016-2021, its current engagement activities and the manner in which it holds a range of bodies to account including the Scottish Government, Health Boards, Integration Authorities and Regulators. As an exemplar, he described how the Committee had called for a better and more transparent system for accessing new medicines, they had achieved consensual cross-party support and the Scottish Government are introducing a new system.

The afternoon session was opened by Dame Denise Coia who provided an overview of the work of NHS Healthcare Improvement Scotland and the opportunities arising for quality improvement through health and social care integration. She began by focusing on the NHS HIS integrated cycle of 
improvement comprised of three key strands - evidence, improvement and scrutiny. After detailing the constituent parts of NHS HIS, she provided key examples of current activity. These included the iHub improvement resource for Health \& Social Care Partnerships and Health Boards, the focus on Integrated Systems Flow and Effective Care Pathways and GP clusters. In closing, the Salford Together 'My Wellbeing Plan' was provided as an example of how health and social care can be improved.

Mr John Burns outlined the ambitions for the NHS in Scotland in the context of the Quality Strategy and in particular that all care provided is patient-centred, safe, effective and we have the appropriate quality infrastructure. He then provided an overview of the literature in relation to quality improvement and safety in which leadership is key; highlighting that there is strong evidence that organisations that are highly successful in safety are generally successful in operational performance and have engagement at all levels of the organisation. Using his own NHS Board as an example, he then provided an overview of the factors required to create a quality improvement culture and learning organisation - quality infrastructure, ensuring psychological safety for staff (and applying wellbeing methodology), engaging and empowering patients and carers (learning through all interactions), placing quality of care and patient safety above all else, fostering staff development and growth, and embracing transparency unequivocally (learning when things don't go as expected).

Dr Marion Slater provided an insight into the challenges facing recently appointed consultants by providing a range of anonymised case studies of patients whom she had to treat during a busy shift at work. Particular attention was given to the level of self-doubt which can be experienced at such times, including questioning one's own competence and judgement. Building on earlier speakers' themes, $\mathrm{Dr}$ Slater explored the range of factors which can adversely affect organsiational culture including a too narrow focus on performance and targets, and silo working exacerbated by increasing specialisation and decreasing generalism in medicine. Attention was then given to how we can produce a more joyful, engaged workforce which evidence shows can reduce staff burnout and medical errors, increase patient experience and satisfaction, improve team working and reduce staff turnover. ${ }^{15}$ The presentation closed by focusing on multidisciplinary team working, ways in which doctors can both be supported and contribute to quality improvement, and the importance of training, resilience and leadership diversity.

Ms Theresa Fyffe outlined the main requirements for nursing quality improvement - Clinical Leadership; Meaningful measures; Staffing, knowledge, expertise and appropriate skill mix; and a Balance Culture - quality and finance. Factors that impact on quality include - bed occupancy has increased, staff costs per bed are lower, nurses looking after more higher-dependency patients, fewer staff, fewer registered nurses, high sickness and absence, and a fall in direct patient care. To measure the quality of nursing care more effectively we need real time data embedded within existing structures and decision-making, clear responsibilities and accountability, a culture of improvement, openness and transparency, and greater support for staff. On workforce and staffing, there is evidence that lower registered nurse staffing levels are associated with the worst patient outcomes. A nursing workforce that is fit for purpose and appropriately resourced is required. The critical role of the senior charge nurse in leading safe, effective, patient care needs to be recognised, respected and properly remunerated.

Dr Catherine Calderwood reflected on her personal interest in the subject of the stakeholder meeting arising from having acted as the obstetrician on the panel of the Morecambe Bay Inquiry. She then provided an overview of the Realistic Medicine workstream launched with her Chief Medical Officer's Annual Report in 2014-15. This aims to change our style of care to shared decision-making, build a personalised approach to care, reduce harm and waste, reduce unnecessary variation in practice and outcomes, manage risk better, and to encourage us to become improvers and innovators. Dr Calderwood provided case study examples with which to illustrate how she believed Realistic Medicine could be practised from a patient's perspective and provided a summary of feedback received in response to the launch of Realistic Medicine.

Professor Michael Deighan and Dr Andrew Corbett-Nolan highlighted the work they had undertaken for the Department of Health in England in relation to An organisation with a memory. ${ }^{16}$ Particular attention was given to their work in developing the Integrated Governance Handbook for the NHS in England and their work in supporting NHS Trusts and Unified Trusts in Northern Ireland to improve governance both within and between organisations and to extend governance to include greater emphasis on the quality of care provided.

\section{Summary of themes to emerge}

\section{The following themes emerged throughout the day:}

- team working and engagement between managers, doctors and other health professions have to be improved if we are to prevent further serious failings in care and to drive quality improvement

- it is the responsibility of leaders to set and improve the organisational culture, and for all others to contribute to this

- all staff have a professional responsibility to raise, and should be supported in raising, concerns regarding standards of care

- staff should be supported in becoming more resilient;

- it is essential that robust governance is in place and constantly being developed

- investigation of failings should be consistent, transparent and conducted externally

- doctors often have little training in management; in contrast medical managers have more understanding of the challenges faced within the NHS

- silo thinking and working must be tackled and broken down at all levels 
- there is a need to develop shared learning, training and CPD involving managers, doctors and other health professions, starting from an early stage in their careers

- in developing greater opportunities for shared learning, attention must be given to addressing workload to facilitate this

- greater professional accountability could be achieved by enhancing the national appraisal scheme for all managers to include a formal requirement to undertake CPD

- real-time medical and nursing data is required to drive quality improvement

- there is much that is good about the NHS in Scotland; we need to demonstrate how much we value our workforce and share good examples of practice more effectively

- we need to educate and support politicians and government in championing change
In the weeks following the National Stakeholder meeting concerns were expressed about possible serious failings in care reported in other hospitals and the Care Quality Commission published a major review finding that the NHS is still missing opportunities to learn from patient deaths in England. ${ }^{17-20}$ Following on from the earlier report on Learning from Serious Failings in Care, and its evolution into Prevention through Learning, the Scottish Academy and the Scottish Institute of Health Managment are committed to continuing this as a core workstream and promoting examples of good practice.

\section{References}

1 Academy of Medical Royal Colleges and Faculties in Scotland. Learning from Serious Failings in Care: Main Report. May 2015 http://www.scottishacademy.org.uk/documents/final-learningfrom-serious-failings-in-care-main-report-290615.pdf

2 Scottish Government. NHS Scotland Quality Strategy - putting people at the heart of our NHS. May 2010. http://www.gov.scot/ Resource/Doc/311667/0098354.pdf

3 Scottish Government. Everyone Matters: 2020 Workforce Vision. 2013. http://www.gov.scot/resource/0042/00424225.pdf

4 Scottish Government. Realistic Medicine. Chief Medical Officer's Annual Report 2014-15. http://www.gov.scot/ Resource/0049/00492520.pdf

5 Titcombe J. Joshua's Story: Uncovering the Morecambe Bay NHS Scandal. Leeds: Anderson Wallace; 2015.

6 Kirkup B. The Report of the Morecambe Bay Investigation. March 2015. https://www.gov.uk/government/uploads/system/uploads/ attachment_data/file/408480/47487_MBI_Accessible_v0.1.pdf

7 Care Quality Commission. The state of health care and adult social care in England 2014/15. October 2015. http://www.cqc.org.uk/ sites/default/files/20151221_cqc_state_of_care_report_web_ accessible.pdf

8 Royal College of Obstetricians \& Gynaecologists. Each Baby Counts. June 2016. https://www.rcog.org.uk/globalassets/documents/ guidelines/research-audit/rcog-each-baby-counts-report.pdf

9 The Bristol Royal Infirmary Inquiry. Learning from Bristol: the report of the Public Inquiry into children's heart surgery at the Bristol Royal Infirmary 1984-95. July 2001. http://webarchive.nationalarchives. gov.uk/20090811143745/http:/www.bristol-inquiry.org.uk/final_ report/the report.pdf

10 Francis R. (Chair). Report of the Mid Staffordshire NHS Foundation Trust Public Inquiry. February 2013. https://www.gov.uk/ government/uploads/system/uploads/attachment_data/ file/279124/0947.pdf

11 Martin G, Siebert S, Howieson B et al. The Changing Experience of Work of Consultants in NHS Scotland. University of Dundee and University of Glasgow; May 2015.
12 Andrews J, Butler M. Trusted to Care: an independent review of the Prince of Wales Hospital and Neath Port Talbot Hospital at Abertawe Morgannwg University Health Board. May 2014. http://www. ambulance.wales.nhs.uk/assets/documents/2e459532-3f274fc6-8091-6445fb417a63635387689176252637.pdf

13 Xu J, Murphy SL, Kochanek KD et al. Deaths: final data for 2013. National Vital Statistics Reports 2016; 64(2). https://www.cdc.gov/ nchs/data/nvsr/nvsr64/nvsr64_02.pdf

14 Weiser TG, Regenbogen SE, Thompson KD et al. An estimation of the global volume of surgery: a modelling strategy based on available data. Lancet 2008; 372: 139-44.

15 Champagne C. How One Company Taught Its Employees How to Be Happier, and What Happened Next. Fast Company 9 April 2013. https://www.fastcompany.com/1682068/how-one-companytaught-its-employees-how-to-be-happier-and-what-happened-next

16 Department of Health. An organisation with a memory. 2000. http://webarchive.nationalarchives.gov.uk/20130107105354/ http:/www.dh.gov.uk/en/Publicationsandstatistics/publications/ publicationspolicyandguidance/browsable/DH_4098184

17 Inquiry call over deaths in childbirth at Crosshouse Hospital. BBC Scotland News 21 November 2016. http://www.bbc.co.uk/news/ uk-scotland-scotland-politics-38043795

18 Mums and babies died because of shameful neglect at two maternity hospitals - the secret report they didn't want you to see. Manchester Evening News 23 November 2016. http://www. manchestereveningnews.co.uk/news/greater-manchester-news/ pennine-acute-maternity-secret-report-12218989

19 Five more 'avoidable' baby deaths in another Scottish maternity unit. The Telegraph 27 November 2016. http://www.telegraph. co.uk/news/2016/11/27/five-avoidable-baby-deaths-anotherscottish-maternity-unit/

20 Care Quality Commission. Learning, candour and accountability: a review of the way NHS Trusts review and investigate the deaths of patients in England. December 2016. http://www.cqc.org.uk/ content/learning-candour-and-accountability 